\title{
Is there an internal cardiac renin-angiotensin system?
}

\author{
A H Jan Danser, Maarten A D H Schalekamp
}

The beneficial effects of the angiotensin converting enzyme (ACE) inhibitors in heart failure appear to be independent - at least in part-of their effects on blood pressure. ${ }^{1}$ It has therefore been proposed that a local reninangiotensin system exists in the heart, but this is still a controversial issue. In our opinion it is justified to use the term "local renin-angiotensin system" when angiotensin II is locally produced by renin synthesised in situ. Only when these conditions are met can such a system be said to operate independently of the kidney. There is, however, a growing body of evidence favouring uptake of renin from the circulation by the heart. The question of local renin formation versus uptake will be addressed in this paper.

\section{Renin-angiotensin system components in cardiac tissue}

Measurements of gene expression, at both protein and mRNA level, have been used to show the existence of a cardiac renin-angiotensin system. Protein measurements cannot be taken as evidence that the protein is synthesised locally. Moreover, such measurements are often hampered by a lack of specificity. For example, the presence of renin activity in tissue extracts may be caused by enzymes other than renin that are capable of generating angiotensin I. Detection of mRNA, particularly when the concentrations are low, does not necessarily mean that the corresponding protein is synthesised locally in physiologically relevant amounts. ${ }^{2}$

We compared the renin level in the heart with its level in blood plasma in normal and nephrectomised pigs. ${ }^{3}$ Angiotensin I generating activity of cardiac tissue was identified as renin by its inhibition by a specific active site directed renin inhibitor. The levels of renin in cardiac tissue (expressed per $\mathrm{g}$ wet weight) were found to be similar to those in plasma (table 1). The tissue levels of renin, therefore, cannot be accounted for by trapped plasma. Both in cardiac tissue and in plasma, renin fell to unde-

Table 1 Renin and angiotensinogen content of cardiac tissue and plasma. Values are means (range), $n=11$

\begin{tabular}{lll}
\hline Tissue & $\begin{array}{l}\text { Renin, fmol ANGI/min } \\
\text { per gram }\end{array}$ & $\begin{array}{l}\text { Angiotensinogen, } \\
\text { pmol/g }\end{array}$ \\
\hline Plasma & $46 \cdot 0(5 \cdot 7-109)$ & $340(195-623)$ \\
Left atrium & $74 \cdot 5(11 \cdot 9-212)^{\star}$ & $71 \cdot 8(24 \cdot 7-169)^{\star}$ \\
Left ventricle & $46 \cdot 6(6 \cdot 4-104)$ & $36 \cdot 0(4 \cdot 1-64 \cdot 8)$ \\
Right atrium & $84 \cdot 2(15 \cdot 1-215)^{\star}$ & $91 \cdot 2(28 \cdot 8-176)^{\star}$ \\
Right ventricle & $52 \cdot 3(8 \cdot 4-118)$ & $57 \cdot 8(29 \cdot 1-107)$ \\
\hline ANG, angiotensin. & & \\
$\star \mathrm{P}<0.05$, atrium $v$ corresponding ventricle (Student's $t$ test for paired observations).
\end{tabular}

tectable levels after nephrectomy (fig 1), suggesting that most, if not all, renin present in the heart originates from the kidney. Indeed, studies in which bolus injections of radiolabelled renin were given to monkeys or rats showed accumulation of radioactivity not only in liver and kidney but also-albeit in lower amounts-in the heart. ${ }^{5}$

Since renin, like ACE, was enriched in a purified cardiac membrane fraction prepared from left ventricular tissue, uptake of kidney derived renin by the heart may occur through binding to cell membranes. ${ }^{3}$ Binding to cell membranes is also suggested by chemical crosslinking studies using membrane fractions prepared from various tissues, including heart and blood vessels. ${ }^{6}$

In support of our findings, studies by others have shown that renin mRNA concentrations in normal cardiac tissue are very low or undetectable. ${ }^{78}$ It remains possible, however, that under pathological conditions ${ }^{9}$ or during foetal development, ${ }^{10}$ the renin gene is expressed in the heart. Cultured neonatal rat cardiac myocytes and fibroblasts contain renin mRNA and have been reported to release renin into the culture medium. ${ }^{10}$

Angiotensinogen concentrations in porcine cardiac tissue are $10-25 \%$ of the levels in plasma, which is compatible with its diffusion from plasma into the interstitium. ${ }^{3}$ On the other hand, substantial concentrations of angiotensinogen mRNA have been found in the heart, ${ }^{11}$ and these levels were increased during postinfarction remodelling. ${ }^{11}$

ACE has been demonstrated in the rat heart by autoradiography, using a radiolabelled ACE inhibitor, ${ }^{12}$ as well as by measurements of its activity in cardiac homogenates. ${ }^{13}$ ACE mRNA is readily detectable in cardiac tissue. ${ }^{13}$ According to some investigators, cardiac ACE is limited normally to the coronary vascular endothelial cells. ${ }^{14}$ Cardiac ACE protein and mRNA are increased following myocardial infarction as well as during pressure overload induced left ventricular hypertrophy. ${ }^{13} 14$ Under these conditions the localisation of ACE may no longer be limited to the endothelium. ${ }^{14}$

The concentration of angiotensin in cardiac tissue (expressed per g wet weight) is similar to the level in plasma, whereas the cardiac tissue concentration of angiotensin II is two to three times the level in plasma (table 2). ${ }^{13} 15$ The cardiac angiotensin levels, therefore, are far too high to be explained by trapped blood or by simple diffusion of angiotensins from plasma into the interstitial fluid. However, such relatively high concentrations cannot be taken as 

and plasma levels of angiotensin I (ANG I) angiotensin II ( $A N G$ II), in non-nephrectomised pigs bars; $n=7$ for $A N G I$ and II, geometric means; $n=11$ for renin and angiotensinogen, means) and nephrectomised pigs (individual points). Plasma concentrations of ANG I, ANG II, renin, and angiotensinogen in nephrectomised animals before nephrectomy are also given. $N D=$ not detectable. From Danser et al ${ }^{3}$ with permission.
Figure 1 Left ventricular renin, and angiotensinogen
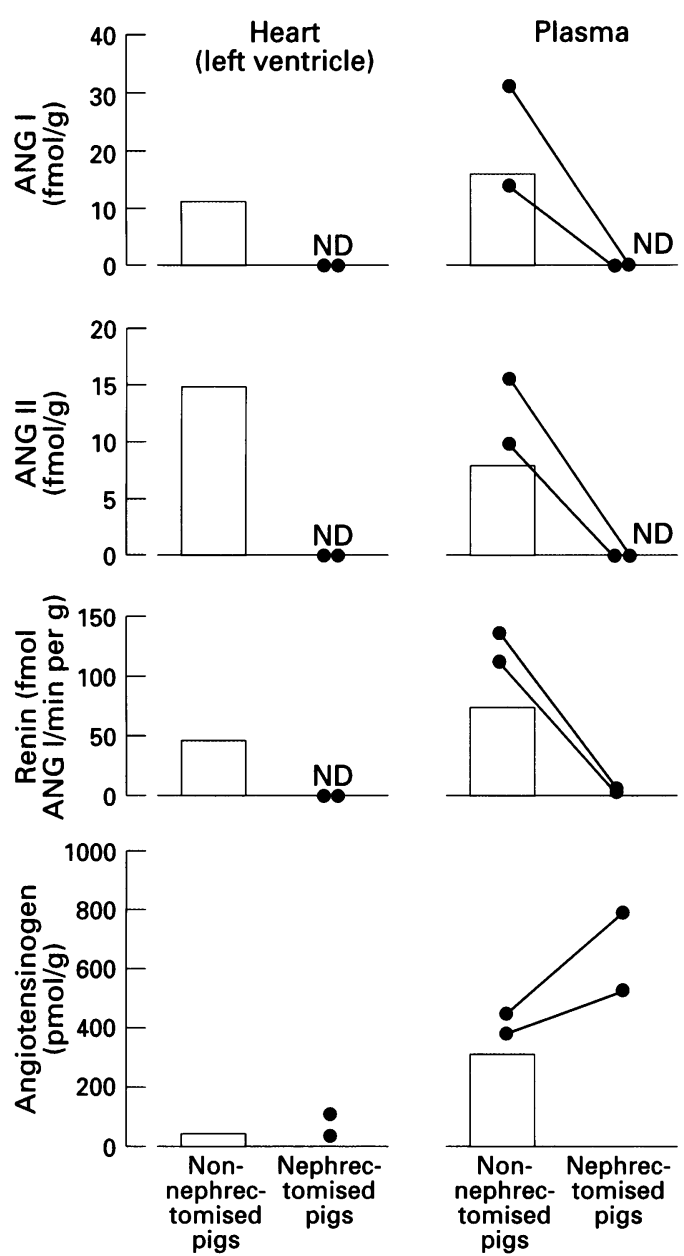

unequivocal evidence that angiotensin I and angiotensin II are generated in cardiac tissue independently of the circulating renin-angiotensin system. For example, angiotensin II may have been sequestered from the circulation by a receptor dependent process.

Levels of angiotensin I and angiotensin II were undetectably low in both plasma and cardiac tissue following bilateral nephrectomy (fig 1)..$^{1315}$ This is a strong indication that cardiac angiotensin generation in vivo depends on renin from the kidney. In vitro experiments have shown that enzymes other than renin, such as cathepsin $\mathrm{D},{ }^{16}$ may also be involved in the generation of angiotensins. On the basis of our results we can rule out that such enzymes are of importance in the heart.

\section{Production of angiotensin II in cardiac tissue}

Local production of angiotensins has been extensively studied with both in vitro and in

Table 2 Angiotensin I and II content of cardiac tissue and plasma. Values are geometric means (range), $n=7$

\begin{tabular}{llll}
\hline Tissue & $\begin{array}{l}\text { ANG I, } \\
\text { fmollg }\end{array}$ & $\begin{array}{l}\text { ANG II, } \\
\text { fmollg }\end{array}$ & $\begin{array}{l}\text { ANG II-ANG I } \\
\text { ratio }\end{array}$ \\
\hline Plasma & $16 \cdot 6(1 \cdot 8-237)$ & $9 \cdot 8(1 \cdot 4-191)^{\star}$ & $0 \cdot 51(0 \cdot 26-1 \cdot 33)^{\star}$ \\
Left atrium & $15 \cdot 1(2 \cdot 9-105) \dagger$ & $25 \cdot 7(11 \cdot 6-244) \dagger$ & $1 \cdot 96(0 \cdot 58-3 \cdot 69)$ \\
Left ventricle & $11 \cdot 1(2 \cdot 0-61 \cdot 0)$ & $14 \cdot 7(2 \cdot 4-217)$ & $1 \cdot 33(0 \cdot 62-12 \cdot 3)$ \\
Right atrium & $21 \cdot 6(8 \cdot 1-56 \cdot 9) \dagger$ & $21 \cdot 1(9 \cdot 2-182) \dagger$ & $0 \cdot 98(0 \cdot 34-3 \cdot 21)$ \\
Right ventricle & $13 \cdot 2(6 \cdot 4-31 \cdot 8)$ & $13 \cdot 4(2 \cdot 5-128 \cdot 8)$ & $1 \cdot 02(0 \cdot 39-9 \cdot 75)$ \\
\hline
\end{tabular}

ANG, angiotensin

tissue $v$ plasma (Mann-Whitney $U$ test for paired observations). tP $<0.05$, atrium $v$ corresponding ventricle. vivo experiments. In studies of the perfused Langendorff rat heart, cardiac production of angiotensin I and angiotensin II could only be demonstrated after the addition of renin to the perfusion buffer. ${ }^{17}$ This suggests that angiotensinogen and ACE, but not renin, are present in the isolated rat heart.

Attempts have been made to study cardiac angiotensin production in the intact animal by measuring the arteriovenous difference for angiotensin I and II across the coronary vascular bed. ${ }^{18}$ However, a large proportion of both angiotensin I and angiotensin II entering the coronary circulation is metabolised during a single passage of blood.

In early studies in sheep, ${ }^{19}$ angiotensin II clearance across the pulmonary and combined systemic vascular beds was calculated from the arteriovenous differences measured across these beds during infusion of high doses of angiotensin II into the pulmonary artery. These studies already indicated that angiotensin II is rapidly degraded and that plasma renin activity is probably insufficient to generate the levels of endogenous angiotensin II measured in circulating blood.

More recently, the regional clearance and metabolism of angiotensin I and angiotensin II have been quantified, both in humans ${ }^{20-22}$ and in pigs, ${ }^{23}{ }^{24}$ by giving constant infusions of radiolabelled ${ }^{125} \mathrm{I}$-angiotensin I or ${ }^{125} \mathrm{I}$-angiotensin II. In humans the infusions were given through an antecubital vein, and in pigs into the left cardiac ventricle. Blood was obtained from various arterial and venous sampling sites for measurements of radiolabelled angiotensin I and angiotensin II. Additional measurements of the levels of endogenous angiotensin I and angiotensin II, and measurements of plasma renin activity at physiological $\mathrm{pH}$ made it possible to estimate how much of the venous angiotensin I could be attributed to arterial delivery, how much to de novo synthesis, and what proportion of de novo synthesised angiotensin I depends on the action of circulating renin on circulating angiotensinogen. It was also possible to calculate how much of the venous angiotensin II originated from arterial delivery and how much originated from conversion of arterially delivered angiotensin I.

It was found that, in the coronary vascular bed, ${ }^{24}$ a major proportion of venous angiotensin I originated from de novo production and that plasma renin activity contributed little to this production. One can therefore conclude that angiotensin $I$ is produced at tissue sites and that part of it is released into the circulation. While most of venous angiotensin I appears not to be generated by the action of circulating renin on circulating angiotensinogen, the level of venous angiotensin I produced at cardiac tissue sites correlated strongly with the level of plasma renin activity. ${ }^{24}$ This, together with our finding in pigs that angiotensin I was virtually absent after nephrectomy, ${ }^{3}$ strongly suggests that it is kidney derived renin that is responsible for the production of angiotensin I by cardiac tissue.

For angiotensin II, the situation is different. Most, if not all, venous angiotensin II appears 
to originate from angiotensin II delivered by the artery and from that generated by conversion of arterially delivered angiotensin I. Thus angiotensin I produced at tissue sites and released into the circulation may have escaped conversion to angiotensin II. It is possible that angiotensin I produced in the tissue enters the blood at a level distal to the site where arterially delivered angiotensin $I$ is converted to angiotensin II by the vascular endothelium, so that this conversion site is bypassed. Angiotensin I formed at tissue sites may enter the circulation at the level of the capillaries or venules, whereas conversion of angiotensin I to angiotensin II occurs at the level of the arterioles. Alternatively, angiotensin II is produced in the tissue and may remain there.

The studies described above are limited to measurements of angiotensins in the circulation. We have now extended these studies by measuring the cardiac tissue levels of endogenous and radiolabelled angiotensin $I$ and angiotensin II in pigs during ${ }^{125} \mathrm{I}$-angiotensin I infusion into the left cardiac ventricle. ${ }^{25}$ Such measurements can be used to estimate the contribution of angiotensins from the circulation to the angiotensin levels in cardiac tissue. Our preliminary results indicate that the cardiac ${ }^{125}$ I-angiotensin I concentrations are less than $5 \%$ of the levels in plasma, whereas the concentrations of cardiac ${ }^{125} \mathrm{I}$-angiotensin II are $85-90 \%$ of plasma ${ }^{125}$ I-angiotensin II. In these experiments the cardiac tissue concentration of angiotensin I was similar to the plasma concentration, while the cardiac tissue level of angiotensin II was four to five times higher than plasma angiotensin II. It was calculated that more than $70 \%$ of the angiotensin II present in cardiac tissue is not derived from angiotensin $I$ in the circulation, and that more than $90 \%$ of cardiac angiotensin I is produced in the tissue itself.

As mentioned above, our measurements of circulating angiotensins during ${ }^{125} I$-angiotensin I infusion into the left cardiac ventricle provided evidence for release of angiotensin I from cardiac tissue sites. These measurements of circulating angiotensins provided no evidence for the release of tissue angiotensin II into the circulation. Thus our data cumulatively indicate that both angiotensin I and angiotensin II are generated by cardiac tissue, and that of these locally generated angiotensins, only angiotensin $\mathrm{I}$ is released into the circulation. Possibly, angiotensin I and angiotensin II are formed in different tissue compartments which are not all capable of exchanging freely with the circulation.

\section{Function of cardiac angiotensin II}

In view of the beneficial effects of ACE inhibitors in heart failure, where regression of cardiac hypertrophy and inhibition of postinfarction remodelling were observed, it has been postulated that angiotensin II acts as a growth factor in the heart. ${ }^{26}{ }^{27}$ Indeed, in isolated cardiac cells, angiotensin II induces hyperplasia (fibroblasts) ${ }^{28}$ or hypertrophy (myocytes). ${ }^{29}$ Angiotensin II also stimulates collagen production by cardiac fibroblasts. ${ }^{30}$ These effects are most probably mediated by the $\mathrm{AT}_{1}$ receptor. Recent reports suggest that the $\mathrm{AT}_{2}$ receptor, which appears to be present in the fetal but not in the adult heart, ${ }^{31}$ is involved in antiproliferation. ${ }^{32}$

Apart from being a growth/antigrowth factor, cardiac angiotensin II may also regulate coronary flow and cardiac contractility. The effect on cardiac contractility is either a direct, $\mathrm{AT}_{1}$ receptor dependent, action on cardiac myocytes, or an indirect effect through presynaptic stimulation of adrenergic nerve endings. Studies on the effects of angiotensin II on cardiac inotropy are conflicting. ${ }^{33} 34$ Part of the conflicting results may be explained by species differences. ${ }^{34}$ In addition, most studies on the cardiac haemodynamic effects of angiotensin II have employed the use of ACE inhibitors. ACE acts on substrates other than angiotensin I (for example, bradykinin and substance P). Consequently, the effects of ACE inhibition on cardiac contractility may not necessarily be due only to the inhibition of angiotensin II formation.

Angiotensinogen is the only known substrate of renin. We therefore used a renin inhibitor to investigate the cardiac haemodynamic effects of angiotensin II. ${ }^{35}$ During intracoronary infusion of the specific renin inhibitor-remikiren - in pigs, a dose dependent depressant effect on cardiac contractility was observed. This effect was significantly diminished after pretreatment with a selective $\mathrm{AT}_{1}$ receptor antagonist. The doses of remikiren required to cause cardiodepression were at least one order of magnitude higher than those required to suppress plasma angiotensin II. These data support the contention that myocardial contractility is increased by renin dependent angiotensin II formation in the heart.

\section{Possible implications}

The existence of a so called local renin-angiotensin system in the heart is still a matter of debate. All renin-angiotensin system components are present in cardiac tissue, and both angiotensin I and angiotensin II are produced in the heart. However, the renin responsible for this local angiotensin production, at least under normal circumstances, appears to originate from the circulation and is therefore kidney derived. Thus a local renin-angiotensin system, in the sense that the renin-angiotensin system components necessary for angiotensin II production are synthesized in situ, does not appear to exist in the normal heart.

In spite of the fact that the cardiac reninangiotensin system appears to depend on renin from the kidney, there are still many ways by which the heart may regulate its own angiotensin II production. Membrane binding could be a mechanism by which kidney derived renin is sequestered in the heart. ${ }^{3}$ Renin binding sites have been reported, and a renin binding protein has been identified in various tissues, including the heart. ${ }^{36} 37$ The density of such binding sites and the concen- 
Figure $2 A C E$ activity in human left ventricular tissue of males (filled symbols) and females (empty symbols) with the $I I, I D$, and $D D$ genotype. $D D$ v ID + II: $P<0.01$ $I$ and $D$ refer to an insertion (I) and deletion (D), respectively, in intron 16 of the ACE gene. ${ }^{38} 39$

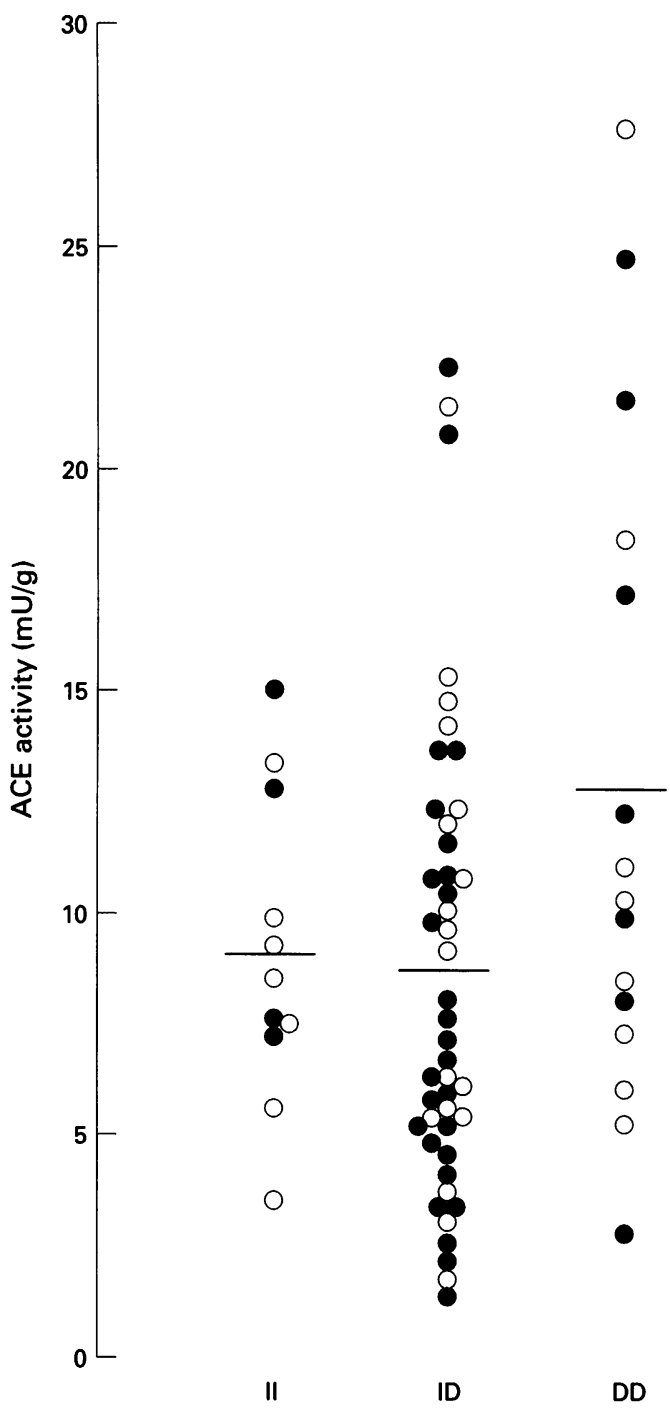

tration of renin binding protein may vary, and this could modify the tissue production of angiotensin I and angiotensin II. Local concentrations of ACE may also vary. The ACE levels in the human heart are, in part, determined by the so called insertion/deletion ACE gene polymorphism (fig 2). ${ }^{38}{ }^{39}$ Also, enzymatic degradation of angiotensin II and $\mathrm{AT}_{1}$ receptor mediated endocytosis could influence the angiotensin II concentrations at the cellular and subcellular level. Finally, under certain pathological conditions, renin may be produced in the heart itself, ${ }^{10}$ and this would create the possibility for the heart to regulate its own angiotensin II production, independent of the kidney.

More detailed knowledge of the actual sites of angiotensin II production in the heart and on its regulation will further illuminate the role of the renin-angiotensin system in cardiac function, growth, and remodelling, and its contribution to the cardiac effects of ACE inhibitors, $\mathrm{AT}_{1}$ receptor antagonists, and renin inhibitors.

\section{Summary}

The beneficial effects of angiotensin converting enzyme (ACE) inhibitors in heart failure appear to be independent, at least in part, of their effect on blood pressure. The existence of a local cardiac renin angiotensin system is often suggested as an explanation. It has been known for some time that a substantial proportion of arterially delivered angiotensin $I$ is converted to angiotensin II by ACE of the coronary vascular endothelium. The levels of angiotensin II in cardiac tissue are several times the levels of angiotensin II in circulating blood. Recent evidence suggests that most of the angiotensin II in the heart is not derived from angiotensin $I$ in the circulation, and that most of the angiotensin I in cardiac tissue is generated in the tissue itself. On the other hand, renin mRNA levels are very low or undetectable in the normal heart. In addition, studies on the effects of bilateral nephrectomy on the cardiac tissue levels of renin, angiotensin I, and angiotensin II in pigs have indicated that cardiac renin originates from the kidney and that cardiac generation of angiotensin I and angiotensin II depends on renin from the kidney. Intracardiac synthesis of renin may occur under pathological conditions and during fetal development. The fact that angiotensins are generated by the heart raises the possibility of local mechanisms to regulate the concentrations of these peptides at certain tissue sites. For example, preliminary evidence suggests that binding of renin to cardiac membranes is a mechanism by which renin is taken up by the heart. A specific renin binding protein has been identified in cardiac tissue. Cardiac ACE levels may also influence local angiotensin II formation and are, in part, determined by the so called insertion/deletion ACE gene polymorphism. More detailed knowledge on the site of angiotensin generation and on its regulation will improve our understanding of the role of the renin-angiotensin system in cardiac function, hypertrophy, and postinfarction remodelling.

1 Linz W, Schaper J, Wiemer G, Albus U, Schölkens BA Ramipril prevents left ventricular hypertrophy with myocardial fibrosis without blood pressure reduction: a one year study in rats. Br f Pharmacol 1992;107:970-5.

2 von Lutterotti N, Catanzaro DF, Sealey JE, Laragh JH. Renin is not synthesized by cardiac and extrarenal vascular tissues. A review of experimental evidence. Circulation 1994;89:458-70.

3 Danser AH, van Kats JP, Admiraal PJ, Derkx FH, Lamers $\mathrm{JM}$, Verdouw PD, et al. Cardiac renin and angiotensins. Uptake from plasma versus in situ synthesis. Hypertension 1994;24:37-48.

4 Skeggs LT, Dorer FE. Incorporation of labeled renin into the tissues of the rabbit. Am 7 Hypertens 1989;2:768-79.

5 Hiruma M, Kim S, Ikemoto F, Murakami K, Yamamoto $\mathrm{K}$. Fate of recombinant human renin administered exogenously to anesthetized monkeys. Hypertension 1988 12:317-23.

6 Campbell DJ, Valentijn AJ. Identification of vascular reninbinding proteins by chemical cross-linking: inhibition of binding of renin by renin inhibitors $f$ Hypertens binding of renin

7 Ekker M, Tronik D, Rougeon F. Extra-renal transcription of the renin genes in multiple tissues of mice and rats. of the renin genes in multiple tissues of
Proc Natl Acad Sci USA 1989;86:5155-8.

8 Iwai N, Inagami T. Quantitative analysis of renin gene expression in extrarenal tissues by polymerase chain reacexpression in extrarenal tissues by polym

9 Boer PH, Ruzicka M, Lear W, Harmsen E, Rosenthal J, Leenen FH. Stretch-mediated activation of cardiac renin Leenen FH. Stretch-mediated activation

10 Dostal DE, Rothblum KN, Chernin MI, Cooper GR, Baker KM. Intracardiac detection of angiotensinogen and renin: a localized renin-angiotensin system in the and renin: a localized renin-angiotensin system in
neonatal rat heart. $A m \mathcal{F}$ Physiol 1992;263:C838-50.

neonatal rat heart. Am $\mathcal{F}$ Physiol 1992;263:C838-50.
11 Lindpaintner K, Lu W, Niedermajer N, Schieffer B, Just $\mathrm{H}$, Ganten D, et al. Selective activation of cardiac angio$\mathrm{H}$, Ganten $\mathrm{D}$, et al. Selective activation of cardiac angiotensinogen gene expression in post-infarction ventricular
remodeling in the rat. $¥ \mathrm{Mol}$ Cell Cardiol 1993;25:133-43. 
12 Yamada H, Fabris B, Allen AM, Jackson B, Johnston CI, Mendelsohn AO. Localization of angiotensin converting enzyme in rat heart. Circ Res 1991;68:141-9.

13 Schunkert H, Dzau VJ, Tang SS, Hirsch AT, Apstein CS, Lorell $\mathrm{BH}$. Increased rat cardiac angiotensin converting enzyme activity and mRNA expression in pressure overload left ventricular hypertrophy. Effects on coronary resistance, contractility, and relaxation. f Clin Invest resistance, contractil

14 Falkenhahn M, Franke F, Bohle RM, Zhu YC, Stauss HM, Bachmann $\mathrm{S}$, et al. Cellular distribution of angiotensinconverting enzyme after
Hypertension 1995;25:219-26.

15 Campbell DJ, Kladis A, Duncan AM. Nephrectomy, converting enzyme inhibition, and angiotensin peptides. Hypertension 1993;22:513-22.

16 Hackenthal E, Hackenthal R, Hilgenfeldt U. Isorenin, pseudorenin, cathepsin $\mathrm{D}$ and renin. A comparative enzymatic study of angiotensin-forming enzymes. Biochim Biophys Acta 1978;522:574-88.

17 Lindpaintner $\mathrm{K}$, Jin MW, Niedermajer $\mathrm{N}$, Wilhelm MJ, Ganten D. Cardiac angiotensinogen and its local activation in the isolated perfused beating heart. Circ Res 1990;67:564-73.

18 Santos RA, Brum JM, Brosnihan KB, Ferrario CM. The renin-angiotensin system during acute myocardial ischemia in dogs. Hypertension 1990;15 (Suppl I):I121-7.

19 Fei DT, Scoggins BA, Tregear GW, Coghlan JP. Angiotensin I, II, and III in sheep. A model of angiotensin production and metabolism. Hypertension 1981;3: 730-7.

20 Admiraal PJ, Derkx FH, Danser AH, Pieterman $\mathrm{H}$, Schalekamp MA. Metabolism and production of angiotensin I in different vascular beds in subjects with hypertensin I in different vascular beds in

21 Admiral PI, Derk FH, Danser AH, Pieterman H, Schalekamp MA. Intrarenal de novo production of Schalekamp MA. Intrarenal de novo production of
angiotensin I in subjects with renal artery stenosis. angiotensin I in subjects with

22 Admiraal PJ, Danser AH, Jong MS, Pieterman H, Derkx FH, Schalekamp MA. Regional angiotensin II production in essential hypertension and renal artery stenosis. Hypertension 1993;21:173-84

23 Danser AH, Koning MM, Admiraal PJ, Derkx FH, Verdouw PD, Schalekamp MA. Metabolism of angiotensin $\mathrm{I}$ by different tissues in the intact animal. $A m \mathcal{F}$ Physiol 1992;263:H418-28.

24 Danser AH, Koning MM, Admiraal PJ, Sassen LM, Derkx FH, Verdouw PD, et al. Production of angiotensins I and II at tissue sites in intact pigs. Am $\mathcal{F}$ Physiol 1992;263: H429-37.

25 van Kats JP, Danser AH, van Meegen JR, Verdouw PD, Schalekamp MA. Origin of angiotensin I and II in the heart [abstr]. Circulation 1995;92 (suppl I):I28.

26 Ruzicka M, Yuan B, Leenen FH. Effects of enalapril versus losartan on regression of volume overload-induced car- diac hypertrophy in rats. Circulation 1994;90:484-91.

27 Schieffer B, Wirger A, Meybrunn M, Seitz S, Holtz J, Riede UN, et al. Comparative effects of chronic angiotensin-converting enzyme inhibition and angiotensin II type 1 receptor blockade on cardiac remodeling after myocardial infarction in the rat. Circulation 1994;89:2273-82.

28 Fujisaki $H$, Ito $H$, Hirata $Y$, Tanaka $M$, Hata $M, L$ in $M$, et al. Natriuretic peptides inhibit angiotensin II-induced proliferation of rat cardiac fibroblasts by blocking endothelin-1 gene expression. $\mathcal{F}$ Clin Invest 1995;96: 1059-65.

29 Miyata S, Haneda T. Hypertrophic growth of cultured neonatal rat heart cells mediated by type 1 angiotensin II receptor. $A m$

30 Brilla CG, Zhou G, Matsubara L, Weber KT. Collagen metabolism in cultured adult rat cardiac fibroblasts: response to angiotensin II and aldosterone. $\mathcal{F} \mathrm{Mol}$ Cell Cardiol 1994;26:809-20.

31 Matsubara $H$, Kanasaki $M$, Murasawa S, Tsukaguchi $Y$, Nio $Y$, Inada $M$. Differential gene expression and regulation of angiotensin II receptor subtypes in rat cardiac fibroblasts and cardiomyocytes in culture. $\mathcal{F}$ Clin Invest 1994;93:1592-601.

32 Stoll M, Steckelings UM, Paul M, Bottari SP, Metzger R, Unger $\mathrm{T}$. The angiotensin AT2-receptor mediates inhibition of cell proliferation in coronary endothelial cells. $\mathcal{F}$ Clin Invest 1995;95:651-7.

33 Holubarsch C, Hasenfuss G, Schmidt-Schweda S, Knorr A, Pieske B, Ruf T, et al. Angiotensin I and II exert inotropic effects in atrial but not in ventricular human myocardium. An in vitro study under physiological experimental conditions. Circulation 1993;88:1228-37.

34 Ishihata $A$, Endoh $M$. Species-related differences in inotropic effects of angiotensin II in mammalian ventricuinotropic effects of angiotensin II in mammalian ventricular muscle: receptors, subtypes and phosph

35 van Kats JP, Sassen LM, Danser AH, Polak MP, Soei LK, Derkx FHM et al. Assessment of the role of the reninangiotensin system in cardiac contractility utilizing the renin inhibitor. Br f Pharmacol 1996;177:891-906.

36 Gahnem F, Catanzaro DF, Sealey JE. High affinity uptake of renin and prorenin by rat tissues [abstr]. Hypertension 1994;24:397.

37 Tada M, Takahashi S, Miyano M, Miyake Y. Tissue-specific regulation of renin-binding protein gene expression in rats. F Biochem 1992;112:175-82.

38 Danser AH, Schalekamp MA, Bax WA, Massen van den Brink A, Saxena PR, Riegger GA, et al. Angiotensin-converting enzyme in the human heart. Effect of the deletion/insertion polymorphism. Circulation 1995;92:1387-8.

39 Rigat B, Hubert C, Alhenc-Gelas F, Cambien F, Corvol P, Soubrier $\mathrm{F}$. An insertion/deletion polymorphism in the angiotensin I-converting enzyme gene accounting for half the variance of serum enzyme levels. 7 Clin Invest 1990; 86:1343-6. 